Article

\title{
The Assessment of Carbon Dioxide Dissociation Using a Single-Mode Microwave Plasma Generator
}

\author{
George Mogildea $^{1}$, Marian Mogildea ${ }^{1, *}$, Cristina Popa ${ }^{2}(1)$ and Gabriel Chiritoi ${ }^{1}$ \\ 1 Institute of Space Science, 077125 Magurele, Romania; george_mogildea@spacescience.ro (G.M.); \\ gabriel.chiritoi@spacescience.ro (G.C.) \\ 2 National Institute for Laser, Plasma and Radiation Physic, Laser Department, 409 Atomistilor St., \\ PO Box MG-36, 077125 Magurele, Romania; cristina.achim@inflpr.ro \\ * Correspondence: marian_mogildea@spacescience.ro
}

Received: 25 February 2020; Accepted: 26 March 2020; Published: 28 March 2020

\begin{abstract}
This paper focuses on the dissociation of carbon dioxide $\left(\mathrm{CO}_{2}\right)$ following the absorption processes of microwave radiation by noncontact metal wire (tungsten). Using a microwave plasma generator (MPG) with a single-mode cavity, we conducted an interaction of microwaves with a noncontact electrode in a $\mathrm{CO}_{2}$ atmosphere. High energy levels of electromagnetic radiation are generated in the focal point of the MPG's cylindrical cavity. The metal wires are vaporized and ionized from this area, subsequently affecting the dissociation of $\mathrm{CO}_{2}$. The $\mathrm{CO}_{2}$ dissociation is highlighted through plasma characterization and carbon monoxide (CO) quantity determination. For plasma characterization, we used an optical emission spectroscopy method (OES), and for CO quantity determination, we used a gas analyzer instrument. Using an MPG in the $\mathrm{CO}_{2}$ atmosphere, we obtained a high electron temperature of the plasma and a strong dissociation of $\mathrm{CO}_{2}$. After $20 \mathrm{~s}$ of the interaction between microwaves and noncontact electrodes, the quantity of $\mathrm{CO}$ increased from $3 \mathrm{ppm}$ to $1377 \mathrm{ppm}(0.13 \% \mathrm{CO})$. This method can be used in space applications to dissociate $\mathrm{CO}_{2}$ and refresh the atmosphere of closed spaces.
\end{abstract}

Keywords: assessment of gases; carbon dioxide dissociation; plasma generator; OES spectroscopy method

\section{Introduction}

The exploration of the Universe has been an important goal of international space programs for decades. The building of the International Space Station (ISS) is the most important engineering feat of humankind, as its existence provides the opportunity to consider further exploration of other planets. NASA and its international partners have recently begun to plan the exploration of Mars, with the hope of bringing new opportunities and knowledge to Earth. Currently, all life-sustaining resources for the ISS are from Earth. Therefore, in order to carry out long-term interplanetary missions, it is necessary to develop new oxygen recycling technologies for astronauts' breathing apparatus. In such conditions, the dissociation of $\mathrm{CO}_{2}$ using plasma systems may be a good choice.

Plasma is a good environment for $\mathrm{CO}_{2}$ dissociation because it contains high energy electrical charges. The disintegration process of gas molecules from plasma is based on the collisions between charged species created in the plasma and neutral particles.

In order to refresh the air inside the spacecraft, electrical energy sourced from its solar panels or nuclear systems can be used to power the plasma systems.

Amongst the different experimental plasma systems developed, the best-known systems are: dielectric barrier discharges (DBD) [1,2], inductively coupled radiofrequency plasma [3,4], microwave discharges [3,5,6], glow discharges [7,8] and gliding arc discharge reactors [9]. 
Experimental studies show that the conversion rate efficiency of $\mathrm{CO}_{2}$ depends on the temperature of the plasma. The energy required to start the $\mathrm{CO}_{2}$ dissociation process is in accordance with Formula (1) [9]. The endothermic plasma-chemical process of $\mathrm{CO}_{2}$ is

$$
\mathrm{CO}_{2} \rightarrow \mathrm{CO}+1 / 2 \mathrm{O}_{2}, \Delta H=2.9 \mathrm{eV} / \text { molecule }
$$

The energy required to start the process of total decomposition of $\mathrm{CO}_{2}$ is displayed in Formula (2) [9].

$$
\mathrm{CO}_{2} \rightarrow \mathrm{CO}+\mathrm{O}, \Delta H=5.5 \mathrm{eV} / \text { molecule }
$$

The $\mathrm{CO}_{2}$ molecule begins to split into $\mathrm{CO}$ and $\mathrm{O}_{2}$ near $2000 \mathrm{~K}$. The decomposition of $\mathrm{CO}_{2}$ can only be carried out at high temperatures (3000-3500 K) [10]. The conversion rate efficiency of $\mathrm{CO}_{2}$ at a plasma temperature of $2000 \mathrm{~K}$ is very small $(<1 \%)$, and at a plasma temperature of $3500 \mathrm{~K}$ it is $60 \%$ [11]. Conversion rates vary between plasma system types, from less than $4 \%$ for DBD [12], to less than $35 \%$ for microwave discharges and gliding arc discharges [6,12].

The gliding arc discharge reactor is attracting considerable attention because it can create both nonthermal and thermal plasmas [11]. The electron temperature of the plasma can rise up to $10,000-23,000 \mathrm{~K}$ in a gliding arc discharge reactor (approximately $2 \mathrm{eV}$ ). [11]

The microwave discharge method is interesting from a scientific point of view, because the microwaves are non-ionizing-radiation and the microwave photons do not have enough energy for the ionization of $\mathrm{CO}_{2}$ molecules. Microwave $\mathrm{CO}_{2}$ dissociation is deemed high in efficiency due to vibrational excitation, as this results in a strong nonequilibrium between vibrational and translational degrees of freedom, which in turn intensifies dissociation. [13] Microwave discharge systems use microwaves to create plasma from the $\mathrm{CO}_{2}$ atmosphere and to dissociate $\mathrm{CO}_{2}$, while the gliding arc discharge method uses an electric current and electrodes to ionize and dissociate $\mathrm{CO}_{2}$.

New methods with more efficient conversion rates are required. Therefore, our research is focused on the dissociation of $\mathrm{CO}_{2}$ produced by the interaction between a microwave field and a noncontact metallic electrode of an MPG. Our method is based on the combination of the gliding arc discharge and the microwave discharge methods. To our knowledge, this is the first time that the $\mathrm{CO}_{2}$, dissociation process using plasma resulting from the interaction between metal wires and microwaves is carried out.

The physical processes involved in microwave interaction with matter are very different. Dielectric materials can volumetrically absorb the electromagnetic energy from the microwave and transform it into heat [14]. Research concerning microwave applications for the heating of metal is seldom completed, as it is well-known that bulk metals reflect microwave radiation, and thus cannot be directly heated [15]. Microwave interaction with metal is restricted to its surface only. Studies from 2001 revealed that metallic powders (tungsten carbide-cobalt) introduced into a multimode cavity in a microwave field can absorb microwave radiation [16].

Other studies conducted in 2009 [17] highlighted that microwave absorption depends on the dimensions of the metallic particle and the frequency of the electromagnetic radiation. In 2009 A. Mondal et al. exposed $\mathrm{Cu}$ powder (particles between 6-385 $\mu \mathrm{m}$ ) to microwaves in a multimode cavity for $10 \mathrm{~min}$. The experimental results showed that the $\mathrm{Cu}$ powder particles with dimensions of $6 \mu \mathrm{m}$ reached temperatures of about $1000^{\circ} \mathrm{C}$, and that microwave absorption of the metallic powders depended on the depth of penetration.

Other recent studies showed that the microwave absorption process can be present in the interaction of nonionizing radiation with metallic objects that have dimensions much larger than the depth of penetration [18].

Using an MPG with a single-mode cylindrical cavity in 2010 [18], we demonstrated that lead metal wires with diameters less than $0.5 \mathrm{~mm}$ can be vaporized and ionized by microwaves. The experiment unfolded in the air at atmospheric pressure. Later, we investigated the possibility of controlling the quantity of metal (lead wires) which are vaporized and ionized in this manner [19]. 
In 2010 we also investigated [20] the microwave heating behaviours of metal wires (lead) in vacuum conditions. The same MPG was used. We found that at $10^{-5}$ millibar pressure, the vaporization and ionization processes of the metal wires did not occur, and the metal wires were only heated up to melting temperature. Thus, metal wires can be heated up to plasma temperature in air conditions at a normal atmosphere and at room temperature, but in vacuum conditions metal wires do not exceed the melting temperature. However, it is possible that air molecules could contribute to the microwave absorption process of metal. In order to investigate whether gas molecules contribute to the microwave heating process, we used metal wire together with a small Teflon piece. The main conclusion of the experiment was that if a metal wire and Teflon piece are exposed to a microwave field, the metal wire generates a strong electric field and the Teflon is heated and decomposed into a gas [21]. This electric field ionizes the Teflon gas, and the heat subsequently generated by the Teflon ion gas is able to vaporize the metal wire. The metal vapors are then ionized in the cylindrical cavity's microwave electric field.

This process is explained by to the Poynting equation displayed in Equation (3) [22].

$$
\vec{P}=\frac{1}{2} \operatorname{Re}\left(\vec{E} \times \vec{H}^{*}\right)=\frac{1}{2} \frac{|E|^{2}}{\eta}
$$

where, $P=$ Poyting vector, $E=$ electric field, $H=$ magnetic field, $\eta=$ impedance of medium.

If the microwave power in the cylindrical cavity increases, the electric field in the metal wire also increases. The microwaves induce strong electric fields in metal wires (3 MV/m to $6 \mathrm{MV} / \mathrm{m}$ [23]). The high electric field causes the ionization of the gas surrounding the metal wire in the high-intensity area. The ions of the plasma interact with the metal wire and vaporize it.

The relationship between the microwave electric field and the current density (conduction and displacement current) of the metal wire is [24,25]:

$$
\mathrm{J}=(\sigma+j \omega \varepsilon) \vec{E}
$$

where: $\mathrm{J}=$ current density in metal wires, $\sigma=$ electrical conductivity of metal wires, $\omega=$ angular frequency, $\varepsilon=$ electrical permittivity, $E=$ electric field.

Other similar experiments were conducted in 2015, in which Popescu S. et al. created titanium plasma from titanium samples [26] in the air at atmospheric pressure. A microwave device with a rectangular cavity was used in the experiment. The plasma column was created when a titanium electrode irradiated by microwaves was brought into contact with a titanium source plate. These studies showed that metallic vapor and $\mathrm{OH}$ radicals were generated in an air atmosphere.

The current objective of this research is the investigation of the dissociation of carbon dioxide $\left(\mathrm{CO}_{2}\right)$ following the absorption processes of microwave radiation by a tungsten $(\mathrm{W})$ wire.

In the experiment, we used an MPG in order to generate the plasma from a noncontact tungsten electrode. The experiment was conducted in a $\mathrm{CO}_{2}$ atmosphere.

The optical emission spectroscopy method (OES) was used to identify the atomic species and determine the plasma's electron temperature. The $\mathrm{CO}$ quantity in the $\mathrm{CO}_{2}$ atmosphere was analyzed using a gas analyzer kit instrument.

\section{Materials and Methods}

The dissociation of $\mathrm{CO}_{2}$ molecules is based on the interaction between microwave fields and a metal wire in a $\mathrm{CO}_{2}$ atmosphere. We used an MPG to generate plasma from a noncontact electrode. The MPG was developed by our team. The microwave plasma generator was introduced into the pressure chamber with a $\mathrm{CO}_{2}$ atmosphere. The volume of the pressure chamber was $0.024 \mathrm{~m}^{3}(24 \mathrm{~L})$ as shown in Figure 1.

The microwave plasma generator consists of a cylindrical cavity, a microwave source (commercial magnetron) with $v=2.45 \mathrm{GHz}, 800 \mathrm{~W}$ emitted power and a power supply (one high voltage power supply for the magnetron anode-PSA, and one low voltage power supply for the filament of the 
thermoelectronic source of the magnetron-PSF). The PSA contains an electronic module to modify the length of the electric impulses (duty factor) of the source that feeds the anode magnetron. Therefore, by changing the duty factor of the anode voltage from the magnetron, we modified the quantity of the vaporized metal and obtained different quantities of dissociated $\mathrm{CO}_{2}$ as a result.

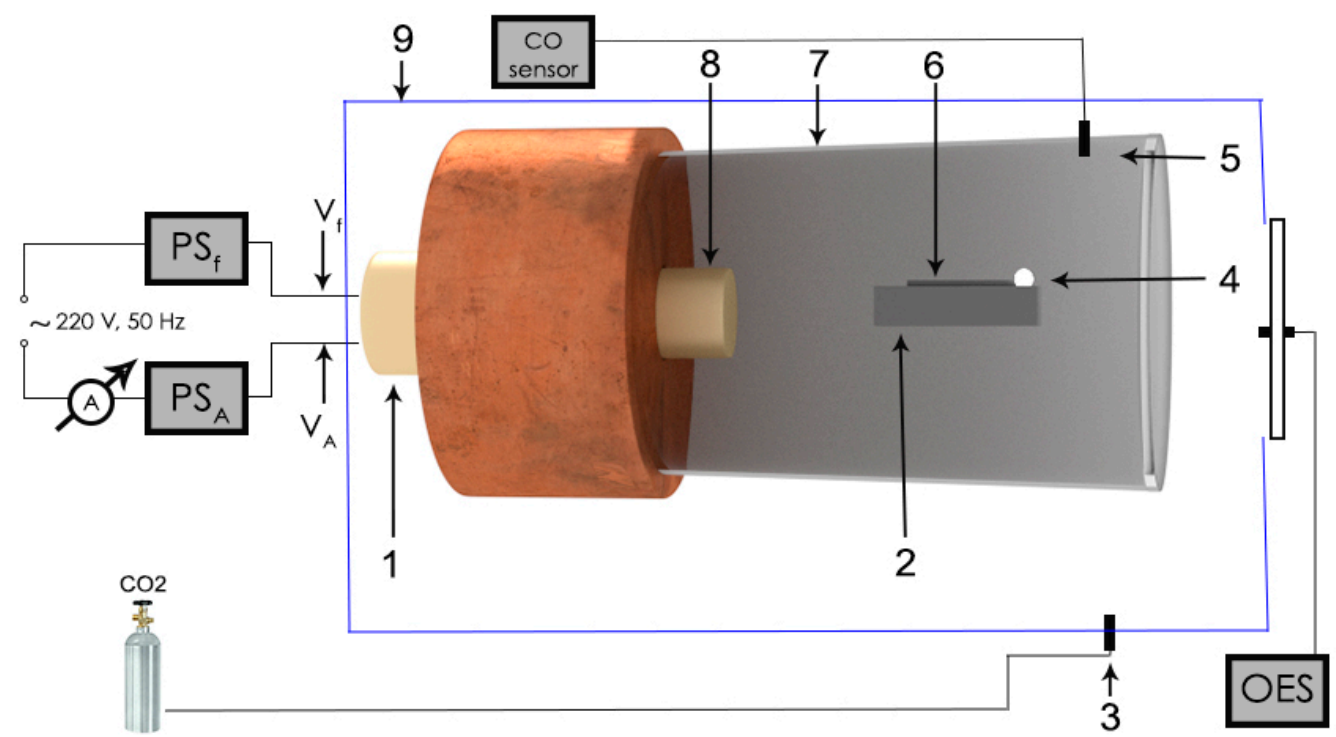

Figure 1. Experimental design of the $\mathrm{CO}_{2}$ dissociation: 1 -magnetron, 2 -ceramic support, $3-\mathrm{CO}_{2}$ connector, 4-high electromagnetic energy region, 5- $\mathrm{CO}_{2}$ sensor, 6 - metallic wire, 7 -cylindrical cavity, 8-magnetron antenna, 9-pressure chamber.

Cylindrical cavity: the TM cylindrical cavity dimensions were calculated with Formula $(5)[22,24]$.

$$
\left(f_{r}\right)_{m n l}^{T M}=\left(\frac{1}{2 \pi \sqrt{\mu \cdot \varepsilon}}\right) \cdot \sqrt{\left(\frac{p_{01}}{a}\right)^{2}+\left(\frac{l \pi}{h}\right)^{2}}
$$

$a$-radius of the cylindrical cavity (m);

$h$-height of the cylindrical cavity $(\mathrm{m})$;

l-Longitudinal mode of the cavity;

$\mu$-Permeability of the medium within cavity $(\mathrm{H} / \mathrm{m})$;

$\varepsilon$-Permittivity of the medium within the cavity $(\mathrm{F} / \mathrm{m})$;

$p_{01}$-First zero of the Bessel function (equal to approximately 2.405);

$f_{r}$-The resonant frequency of the cavity.

The indices mnl of the TM propagation mode refer to the number of half-wavelength variations in the radial, axial and longitudinal directions. The optimal dimensions of the $T M_{011}$ cylindrical cavity are a diameter of $11 \mathrm{~cm}$ and a length of $10.5 \mathrm{~cm}$.

The first preparation step of the experiment was to introduce the noncontact electrode into the cylindrical cavity shown in Figure 2. As the microwave electric field propagates along the axis of the cavity in the $T M_{011}$ propagating mode, the metallic electrode must be positioned along, and as close as possible to the axis.

The high-density energy region (focal point) is located $6.1 \mathrm{~cm}$ from the magnetron antenna, which corresponds to half-wavelength for the $2.45 \mathrm{GHz}$ microwave frequency. One end of the metallic electrode was placed in the focal point of the cylindrical cavity. The noncontact electrode used was a tungsten wire with a diameter of $0.5 \mathrm{~mm}$ and a length of $50 \mathrm{~mm}$. The sample was placed on a ceramic support and introduced into the cavity shown in Figure 2. 


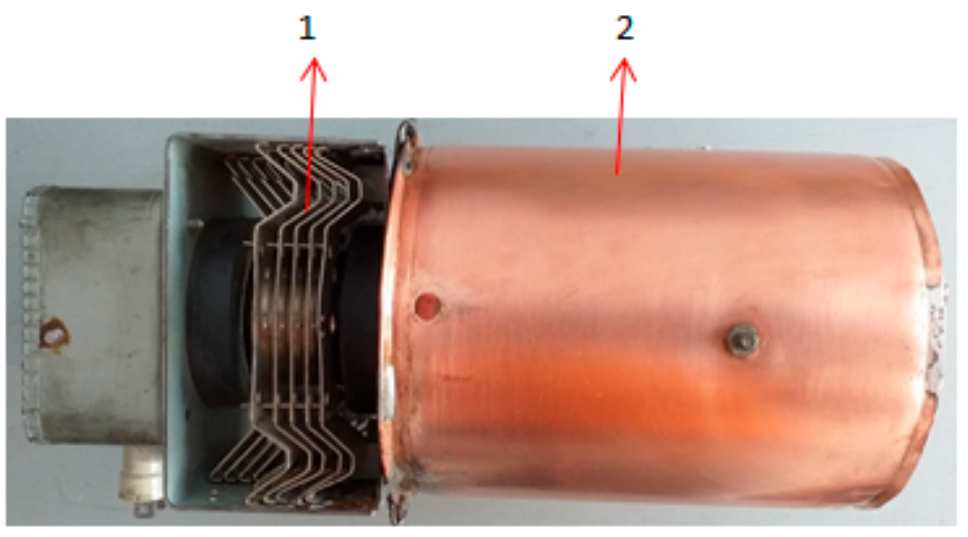

a

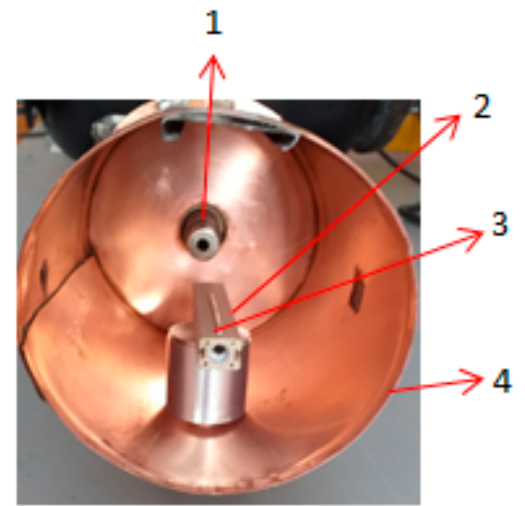

b

Figure 2. The microwave plasma generator: (a) 1-magnetron, 2 -cylindrical cavity lateral view; (b) 1-magnetron antenna, 2-ceramic support, 3-metallic wire; 4-cylindrical cavity front view; (a) Lateral view (b) Front view.

The pressure chamber was filled with $\mathrm{CO}_{2}$ at atmospheric pressure, and the microwave source was turned on. In these conditions, the tungsten wire was exposed to microwaves for $20 \mathrm{~s}$. As displayed in Figure 3, the plasma was created at $700 \mathrm{~W}$ microwave power in a $\mathrm{CO}_{2}$ atmosphere, at normal atmospheric pressure and ambient temperature.

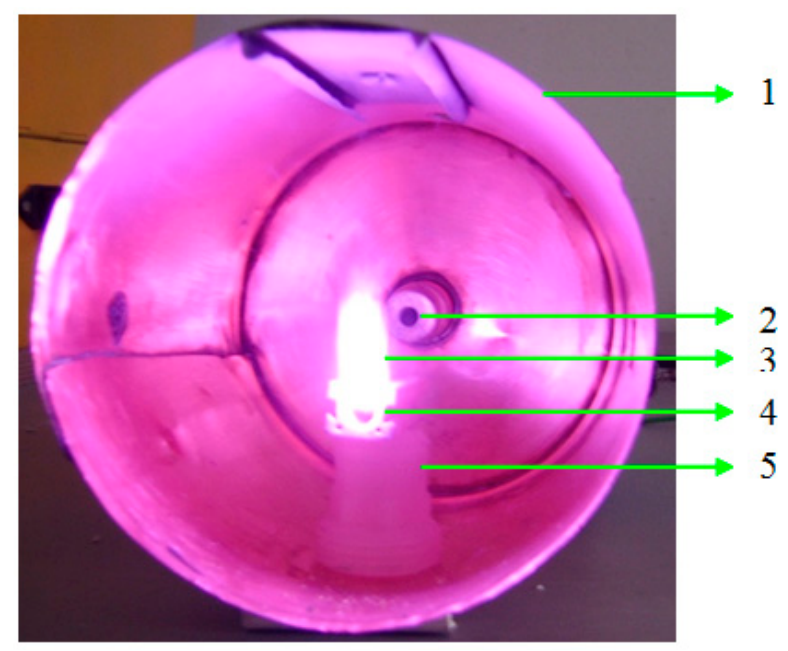

Figure 3. The metallic wire exposed to the microwave field: 1 -cylindrical cavity, 2-magnetron antenna, 3-metallic plasma, 4-ceramic support, 5-plastic support.

The tungsten wire was partially vaporized from this area, as explained in Table 1 . We chose tungsten (W) as a noncontact electrode because this metal has high electrical conductivity which leads to a small rate of metal vaporization [26] as shown in Table 1. The tungsten wire was slowly consummated during the $\mathrm{CO}_{2}$ dissociation process, which allowed us to dissociate $\mathrm{CO}_{2}$ for a long time.

Table 1. Energetic parameters and vaporization rate of the tungsten.

\begin{tabular}{cccc}
\hline Tungsten Wire & $\begin{array}{c}\text { First Ionization Energy } \\
(\mathbf{e V})\end{array}$ & $\begin{array}{c}\text { Vaporization Rate } \\
(\mathbf{m g} / \mathbf{s})\end{array}$ & $\begin{array}{c}\text { Electrical Conductivity } \\
(\mathrm{S} / \mathbf{m})\end{array}$ \\
\hline$(0.5 \mathrm{~mm}$ diameter $)$ & 7.98 & 2 & $2 \times 10^{7}$ \\
\hline
\end{tabular}


Following the interaction between the microwave and the tungsten electrode, we analyzed the plasma components and we determined the $\mathrm{CO}$ quantity in the $\mathrm{CO}_{2}$ atmosphere.

For plasma characterization, we used the optical emission spectroscopy method (OES) [27,28].

Using the Ocean Optics USB 2000 spectrometer, we recorded the optical emission spectrum of the plasma with an integration time of $1 \mathrm{~ms}$.

To determine the $\mathrm{CO}$ concentration in the $\mathrm{CO}_{2}$ atmosphere, we used the CHEMIST 504S gas analyzer kit instrument, which is an instrument that uses an electrochemical sensor to measure the concentration of $\mathrm{CO}$ with a resolution of $2 \times 10^{4} \mathrm{ppm}$.

\section{Results and Discussion}

Microwave plasma is widely investigated because of its potential to provide highly efficient $\mathrm{CO}_{2}$ conversion. Thus far, various experimental microwave devices have been developed. All microwave devices create plasma when microwaves interact directly with a $\mathrm{CO}_{2}$ atmosphere. The dissociation of $\mathrm{CO}_{2}$ is based on the microwave absorption process of $\mathrm{CO}_{2}$. The value of the electron temperature of the plasma obtained with the actual microwave devices does not exceed $7000 \mathrm{~K}[5,10]$.

In our experiment, the dissociation of $\mathrm{CO}_{2}$ was based on the microwave absorption process by metals. This physical process is characterized by Ohm losses [17]. The Ohm loss process is present when a metal wire is crossed by an electric current, or in our experiment, when a noncontact electrode interacts with microwaves.

Therefore, when microwaves interact with a noncontact electrode, a high electric field ( $3 \mathrm{MV} / \mathrm{m}-6 \mathrm{MV} / \mathrm{m}$ ) is generated in the focal point of the cavity, as shown in Figure 1 . When the noncontact electrode comes into contact with the gas atmosphere, the electrode is vaporized and ionized, and the gas is also ionized. The dissociation of $\mathrm{CO}_{2}$ molecules is produced in two ways: the collision of $\mathrm{CO}_{2}$ molecules with electrical charges generated by microwave in a noncontact electrode, and the interaction between the metal's ions and $\mathrm{CO}_{2}$ molecules. In $20 \mathrm{~s}$ of interaction between the noncontact electrode, $\mathrm{CO}_{2}$, and the microwave field, the tungsten electrode was partially vaporized and ionized.

Metallic vapors and ions of the tungsten and ions of the gases such as $\mathrm{CO}, \mathrm{O}_{2}, \mathrm{O}, \mathrm{C}$, etc., were generated in the cylindrical cavity, as displayed in Figures 4 and 5.

The ions were highlighted using the optical emission spectroscopy method (OES) $[27,28]$.

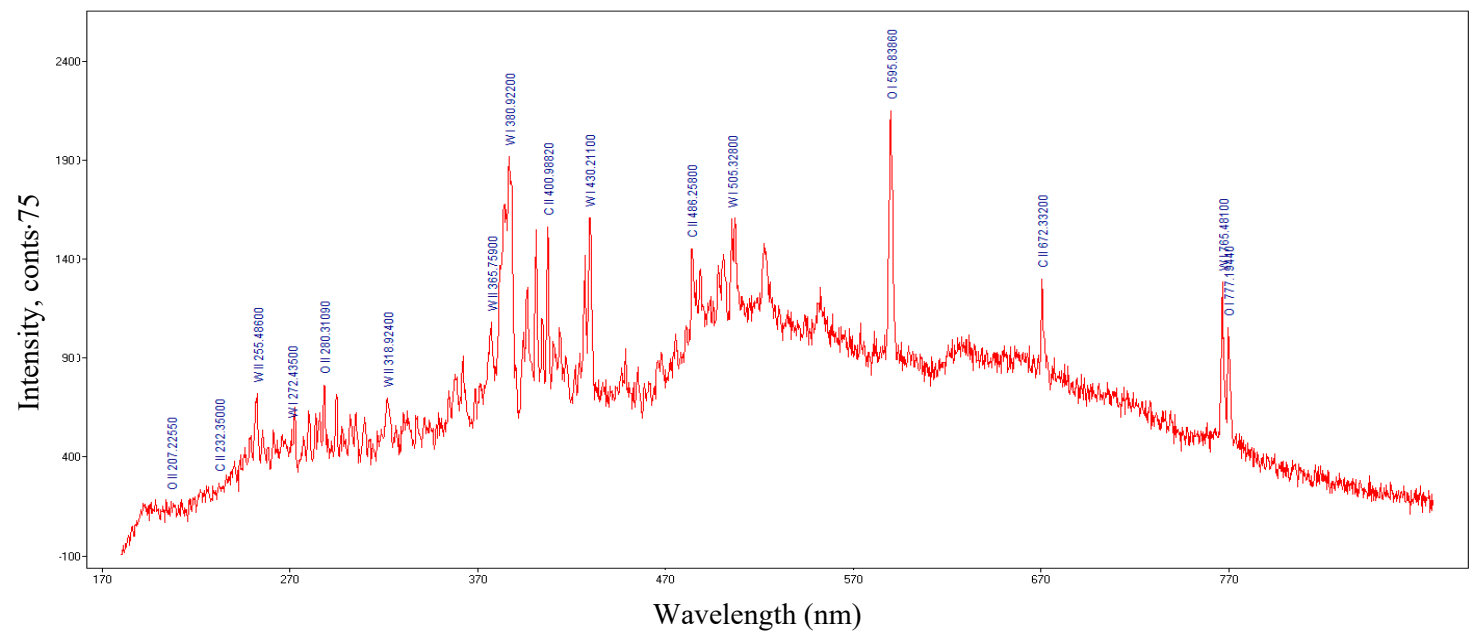

Figure 4. Optical emission spectra of the plasma: Ions generated during $\mathrm{CO}_{2}$ dissociation process.

Spectrum Analyzer software [29] was used to identify optical emission spectra of the plasma. The microwave field created ions of metal, oxygen, and carbon. The ions were observed from the optical emission spectra, shown in Figure 4. Ions of oxygen (OI and OII), carbon (CII) and tungsten (WI and WII) were observed in the plasma emission spectra, displayed in Figure 4. During the $\mathrm{CO}_{2}$ 
dissociation process, other gas molecules such as $\mathrm{CO}$ and molecular oxygen were formed, as shown in Figure 5 [30-32].

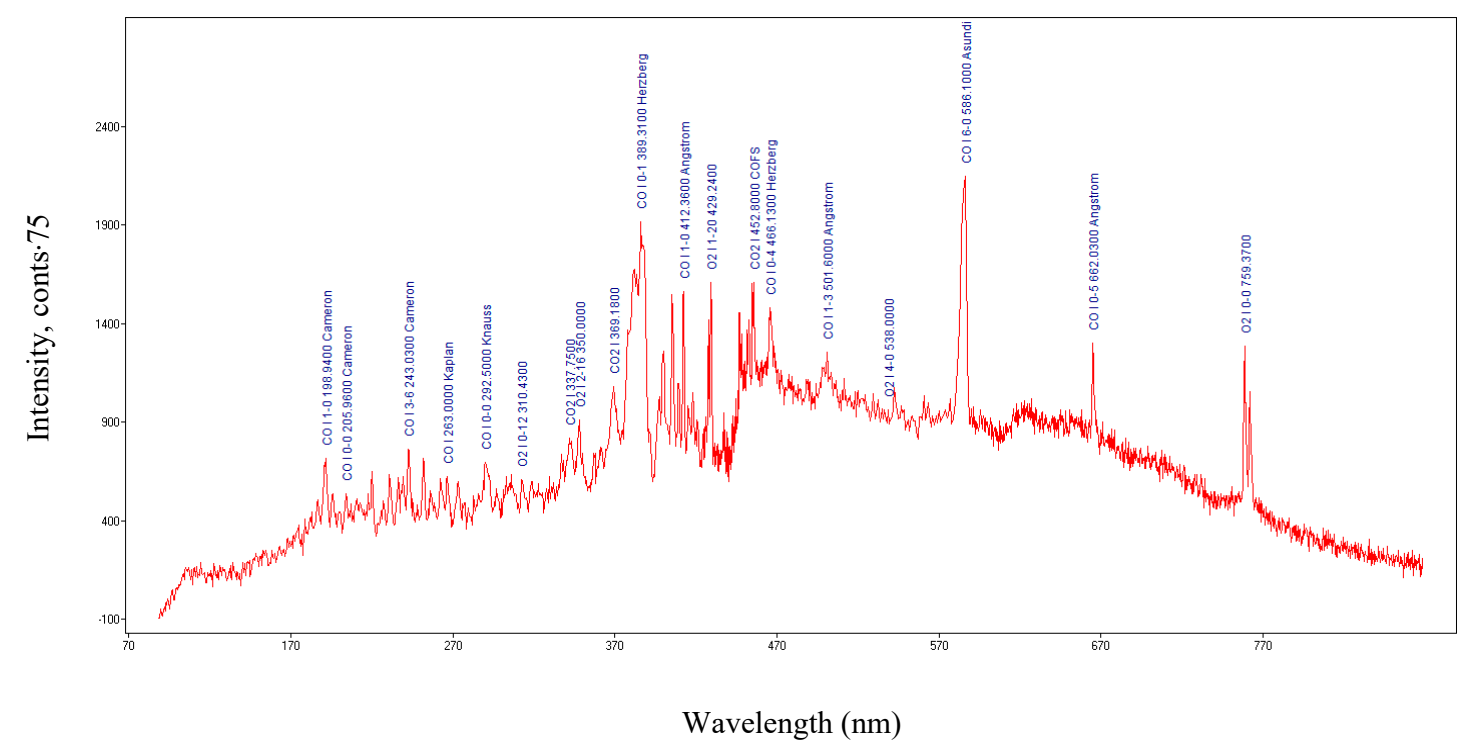

Figure 5. Optical emission spectra of the plasma: The monoxide and oxygen generated during the $\mathrm{CO}_{2}$ dissociation process.

The monoxide and molecular oxygen are highlighted in the optical emission spectra of the plasma in Figure 5. To assess the $\mathrm{CO}_{2}$ dissociation efficiency of our method, we determined the electron temperature of the plasma. The electron temperature of tungsten plasma and oxygen plasma was determined using the Boltzmann plot method, which assumes that local thermodynamic equilibrium (LTE) is met within the plasma. The electron temperature for tungsten ions was $54,000 \mathrm{~K}$, and the electron temperature for oxygen ions was 12,800 K as shown in Figures 6 and 7, respectively.

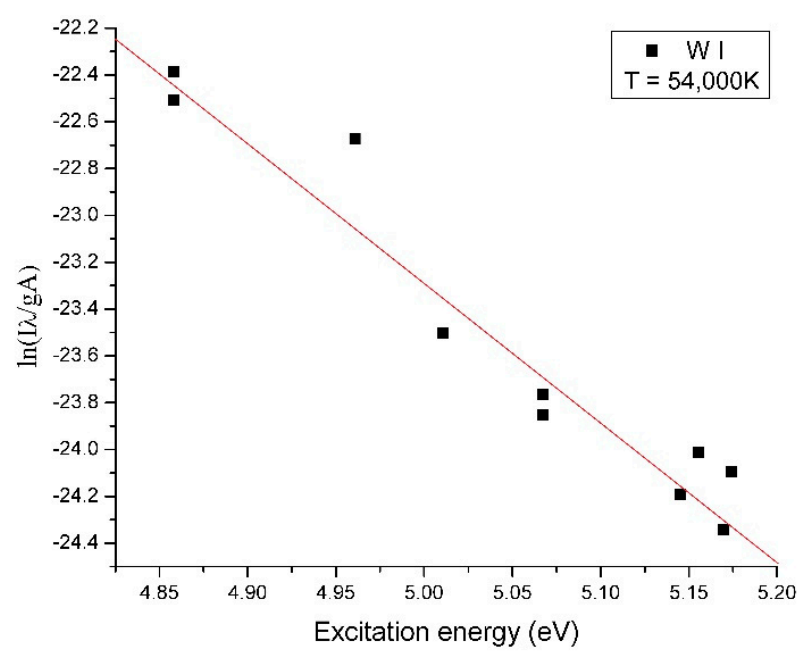

Figure 6. The Boltzmann plot and electron temperature for tungsten ions. 


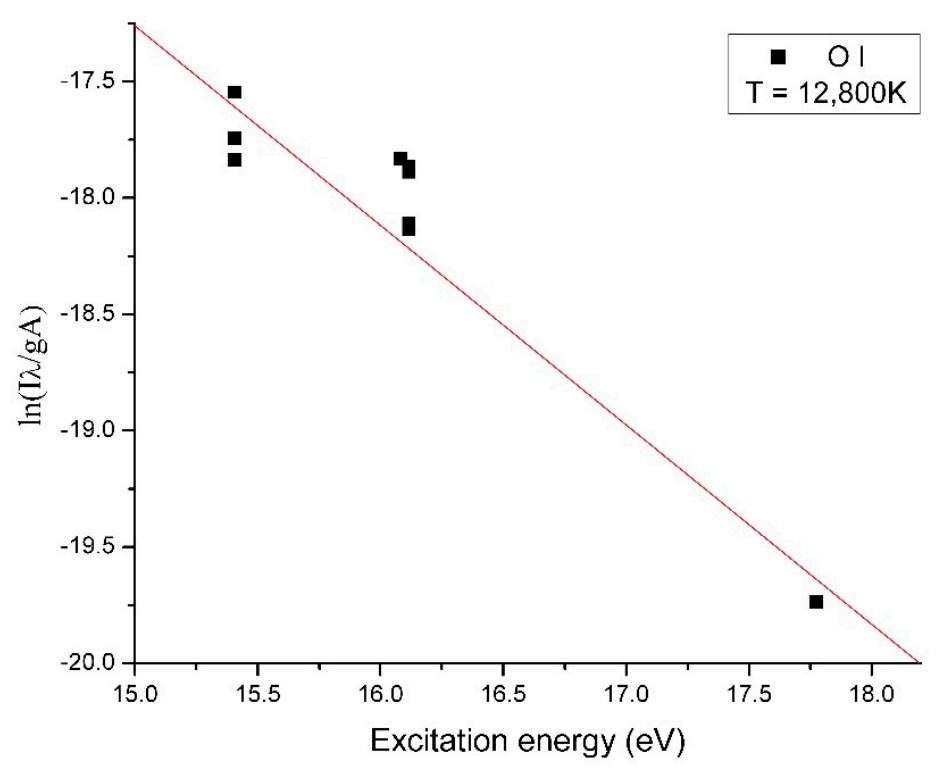

Figure 7. The Boltzmann plot and electron temperature for ions oxygen.

We measured the $\mathrm{CO}$ in the $\mathrm{CO}_{2}$ atmosphere before both starting and stopping the microwave discharge.

The following parameters were recorded: before creating plasma, the concentration of the $\mathrm{CO}$ in the $\mathrm{CO}_{2}$ atmosphere was $3 \mathrm{ppm}$.

After the $20 \mathrm{~s}$ reaction time, (interaction time between the microwave field and metal wire), the quantity of the $\mathrm{CO}$ generated during the $\mathrm{CO}_{2}$ dissociation process was increased to $1377 \mathrm{ppm}$.

\section{Conclusions}

Using a microwave plasma generator, we highlighted that $\mathrm{CO}_{2}$ was dissociated through interaction between metal wires and the microwave field.

During the interaction between the microwave and tungsten wire, thermal plasma and non-thermal plasma were generated.

We obtained a high value for the electron temperature of the plasma $(54,000 \mathrm{~K}$ or $4.7 \mathrm{eV}$ for WI and $12,800 \mathrm{~K}$ or $1.1 \mathrm{eV}$ for OI).

During interaction with the plasma, ions of OII, WII, CII and gases such as $\mathrm{CO}$ and $\mathrm{O}_{2}$ were created.

After $20 \mathrm{~s}$ reaction time, the quantity of $\mathrm{CO}$ increased from $3 \mathrm{ppm}$ to $1377 \mathrm{ppm}$ inside the pressure chamber, meaning that $0.13 \% \mathrm{CO}$ was generated in $24 \mathrm{~L}$ of $\mathrm{CO}_{2}$ in this period.

Using our method, we obtained a high electron temperature of the plasma, and subsequently a better $\mathrm{CO}_{2}$ dissociation efficiency.

Author Contributions: Conceptualization, G.M.; Formal analysis, C.P. and G.C.; Investigation, G.M., M.M. and C.P.; Methodology, G.M. and M.M.; Project administration, M.M.; Resources, M.M.; Software, M.M. and G.C.; Supervision, M.M.; Writing-original draft, G.M. and M.M.; Writing—review \& editing, C.P. All authors have read and agreed to the published version of the manuscript.

Funding: This work was supported by a grant of the Ministry of National Education and Scientific Research by Nucleus programme-contract LAPLAS VI, no. 16N/2019.

Conflicts of Interest: The authors declare no conflict of interest regarding the publication of this paper.

\section{References}

1. Duan, X.; Li, Y.; Ge, W.; Wang, B. Degradation of $\mathrm{CO}_{2}$ through dielectric barrier discharge microplasma. Greenh. Gases: Sci. Technol. 2014, 5, 131-140. [CrossRef]

2. Ray, D.; Saha, R.; Subrahmanyam, C. DBD Plasma Assisted $\mathrm{CO}_{2}$ Decomposition: Influence of Diluent Gases. Catalysts 2017, 7, 244. [CrossRef] 
3. Huang, Q.; Zhang, D.; Wang, N.; Liu, K.; Kleyn, A.W. Carbon dioxide dissociation in non-thermal radiofrequency and microwave plasma. J. Phys. D: Appl. Phys. 2017, 50, 294001. [CrossRef]

4. Spencer, L.F.; Gallimore, A.D. Efficiency of $\mathrm{CO}_{2}$ Dissociation in a Radio-Frequency Discharge. Plasma Chem. Plasma Process. 2010, 31, 79-89. [CrossRef]

5. Kwak, H.S.; Uhm, H.S.; Hong, Y.C.; Choi, E.H. Disintegration of Carbon Dioxide Molecules in a Microwave Plasma Torch. Sci. Rep. 2015, 5, 18436. [CrossRef] [PubMed]

6. Uhm, H.S.; Hong, Y.C.; Shin, D.H. A microwave plasma torch and its applications. Plasma Sources Sci. Technol. 2006, 15, S26-S34. [CrossRef]

7. Corvin, K.K. Dissociation of Carbon Dioxide in the Positive Column of a Glow Discharge. J. Chem. Phys. 1969, 50, 2570. [CrossRef]

8. Lisovskiy, V.A.; Krol, H.H.; Dudin, S.V. Problems Of Atomic Science And Technology. Plasma Physics 2018, 118, 206-209.

9. Nunnally, T.; Gutsol, K.; Rabinovich, A.; Fridman, A.; Gutsol, A.; Kemoun, A. Dissociation of $\mathrm{CO}_{2}$ in a low current gliding arc plasmatron. J. Phys. D: Appl. Phys. 2011, 44, 274009. [CrossRef]

10. Sun, H.; Lee, J.; Do, H.; Im, S.-K.; Bak, M.S. Experimental and numerical studies on carbon dioxide decomposition in atmospheric electrodeless microwave plasmas. J. Appl. Phys. 2017, 122, 033303. [CrossRef]

11. Li, L.; Zhang, H.; Li, X.; Kong, X.; Xu, R.; Tay, K.; Tu, X. Plasma-assisted $\mathrm{CO}_{2}$ conversion in a gliding arc discharge: Improving performance by optimizing the reactor design. J. CO 2 Util. 2019, 29, 296-303. [CrossRef]

12. Zhou, A.; Chen, D.; Ma, C.; Yu, F.; Dai, B. DBD Plasma- $\mathrm{ZrO}_{2}$ Catalytic Decomposition of $\mathrm{CO}_{2}$ at Low Temperatures. Catalysts 2018, 8, 256. [CrossRef]

13. Bekerom, D.C.M.V.D.; Linares, J.M.P.; Verreycken, T.; Van Veldhuizen, E.M.; Nijdam, S.; Berden, G.; A Bongers, W.; Van De Sanden, M.C.M.; Van Rooij, G.J. The importance of thermal dissociation in $\mathrm{CO}_{2}$ microwave discharges investigated by power pulsing and rotational Raman scattering. Plasma Sources Sci. Technol. 2019, 28, 055015. [CrossRef]

14. Kanagasabay, S. Non-ionizing radiation. Curr. Approach. Occup. Health 1982, 2, 134-168.

15. Sun, J.; Wang, W.; Yue, Q. Review on Microwave-Matter Interaction Fundamentals and Efficient Microwave-Associated Heating Strategies. Materials 2016, 9, 231. [CrossRef] [PubMed]

16. Cheng, J.; Roy, R.; Agrawal, D. Experimental proof of major role of magnetic field losses in microwave heating of metal and metallic composites. J. Mater. Sci. Lett. 2001, 20, 1561-1563. [CrossRef]

17. Mondal, A.; Agrawal, D.; Upadhyaya, A. Microwave heating of pure copper powder with varying particle size and porosity. J. Microw. Power Electromagn. Energy 2009, 43, 5-10. [CrossRef]

18. Mogildea, G.; Mogildea, M. Experimental investigation of the metals vaporization and ionization with microwave used as propellant for ionic propulsion. J. Optoelectron. Adv. Mater.-Rapid Commun. 2010, 4, 352-356.

19. Mogildea, M.; Mogildea, G. Experimental research for the mass flow control of the metal vaporized and ionized with microwave used in electric propulsion. J. Optoelectron. Adv. Mater. 2010, 12, 1157-1160.

20. Mogildea, G.; Mogildea, M. Experimental investigation of the microwave electrothermal thruster using metals as propellant. J. Optoelectron. Adv. Mater.-Rapid Commun. 2010, 4, 1826-1829.

21. Madorsky, S.; Hart, V.; Straus, S.; Sedlak, V. Thermal degradation of tetrafluoroethylene and hydrofluoroethylene polymers in a vacuum. J. Res. Natl. Inst. Stand. Technol. 1953, 51, 327. [CrossRef]

22. Chryssomallis, M.; Christodoulou, C. Antenna Radiation Patterns. In Wiley Encyclopedia of Electrical and Electronics Engineering; Wiley: Hoboken, NJ, USA, 1999; Volume 2.

23. Leins, M.; Gaiser, S.; Schulz, A.; Walker, M.; Schumacher, U.; Hirth, T. How to Ignite an Atmospheric Pressure Microwave Plasma Torch without Any Additional Igniters. J. Vis. Exp. 2015, 98. [CrossRef] [PubMed]

24. Nordling, N.; Micci, M. Low-power Microwave Arcjet Performance Testing. IEPC 1997, 97, 89.

25. Dudley, D.G. The IEEE Series on Electromagnetic Wave Theory. IEEE Antennas Propag. Mag. 2006, 48, $126-127$. [CrossRef]

26. Popescu, S.; Jerby, E.; Meir, Y.; Barkay, Z.; Ashkenazi, D.; Mitchell, J.B.A.; Le Garrec, J.-L.; Narayanan, T. Plasma column and nano-powder generation from solid titanium by localized microwaves in air. J. Appl. Phys. 2015, 118, 023302. [CrossRef] 
27. Mogildea, G.; Mogildea, M.; Jivanescu, I.; Porosincu, C.; Lungu, C.; Chiritoi, G.; Mingireanu, F. Direct vaporization and ionization of the metals wires using microwave field. J. Optoelectron. Adv. Mater. 2015, 7, 367-371.

28. Isola, L.M.; Gomez, B.J.A.; Guerra, V. Determination of the electron temperature and density in the negative glow of a nitrogen pulsed discharge using optical emission spectroscopy. J. Phys. D: Appl. Phys. 2009, 43, 015202. [CrossRef]

29. Bazavan, M.; Teodorescu, M.; Dinescu, G. Confirmation of $\mathrm{OH}$ as good thermometric species for gas temperature determination in an atmospheric pressure argon plasma jet. Plasma Sources Sci. Technol. 2017, 26, 075001. [CrossRef]

30. Navrátil, Z.; Trunec, D.; Šmíd, R.; Lazar, L. A software for optical emission spectroscopy-problem formulation and application to plasma diagnostics. Czechoslov. J. Phys. 2006, 56, B944-B951. [CrossRef]

31. Dobrea, S.; Mihaila, I.; Tiron, V.; Popa, G. Optical and mass spectrometry diagnosis of a $\mathrm{CO}_{2}$ microwave plasma discharge. Rom. Rep. Physics. 2014, 66, 1147-1154.

32. Lisovskiy, V.A.; Krol, H.H.; Dudin, S.V. Investigation of DC glow discharge in $\mathrm{CO}_{2}$ using Optical Emission Spectroscopy. Probl. Atomic Sci. Technol. 2018, 6, 206-209.

Sample Availability: Samples of the compounds are available from the authors. 